\title{
To Study the Vitamin D Status in Children with Sepsis Admitted in Intensive Care Unit of a Tertiary Care Centre of North-West Rajsthan
}

\author{
Vikram Yadav ${ }^{1 *}$, Nishant Ahmad², R K Soni ${ }^{3}$, Monika ${ }^{1}$ \\ ${ }^{1}$ Resident, ${ }^{2}$ Senior Resident, ${ }^{3}$ Professor, \\ Department of Paediatrics, S.P Medical College, Bikaner, Rajasthan, India.
}

\begin{abstract}
Background: Vitamin D definitely is a marker of poor health and immobility. When assessing vitamin $\mathrm{D}$ status during critical illness, a number of ICU specific factors like fluid loading and inflammatory status need to be taken into account.

Aim \& objectives: To study the vitamin D status in children with sepsis admitted in intensive care unit of a tertiary care centre of North-west Rajasthan.

Material \& Methods: Patients of either gender, older than 1 year and younger than 12 years with systemic inflammatory response syndrome (SIRS) with suspected or proven sepsis, admitted in PICU were included for the study. The level of vitamin $\mathrm{D}$ was measured by VIDAS ${ }^{\circledR} 25 \mathrm{OH}$ Vitamin D Total, It reflects vitamin $D$ produced cutaneously and that obtained from food and supplements for a reliable indication of vitamin D status.

Results: The present study observed that Out of the total 50 patients with sepsis, $60 \%$ had deficient vitamin $D_{3}$ levels, $24 \%$ had insufficient levels and $16 \%$ had sufficient vitamin $D_{3}$ levels. Most common diagnosis was lower respiratory tract infection (36\%), followed by septicaemia (16\%).

Conclusion: The current picture of vitamin $\mathrm{D}$ and sepsis is one of a research field early in its course with many important links
\end{abstract}

\section{INTRODUCTION}

Vitamin $D$ refers to a group of fat-soluble secosteroids responsible for enhancing intestinal absorption of calcium, iron, magnesium, phosphate and zinc. In humans, the most important compounds in this group are vitamin $D_{3}$ (also known as cholecalciferol) and vitamin $\mathrm{D}_{2}$ (ergocalciferol) 1 . Cholecalciferol and ergocalciferol can be ingested from the diet and from supplements ${ }^{1-3}$. The body can also synthesize vitamin $D$ (specifically cholecalciferol) in the skin, from cholesterol, when sun exposure is adequate (hence its nickname, the "sunshine vitamin").

The importance of vitamin $D$ on bone health and calcium homeostasis has long been understood. However, scientists are beginning to uncover that this steroid hormone has important roles in the optimal functioning of many organ systems. Vitamin $D$ receptors and 25-hydroxyvitamin D-1a-hydroxylase (1-a-OHase) have been discovered in many extra skeletal tissues and the vitamin D response element (VDRE) found in over 900 genes $^{4}$. Furthermore, recent epidemiologic and clinical trials have suggested that optimal vitamin $D$ status may be protective against several chronic illnesses including risk of systemic infection, cardiovascular disease, lung disease and diabetes. ${ }^{5-9}$ Vitamin $D$ is best known for its regulation of calcium and phosphate homeostasis and effects on bone health. Recently it has also been found to regulate innate and adaptive immune function including that provide fertile ground for further investigation. Such investigation is warranted as vitamin $D$ is inexpensive and safe to administer and even incremental benefits in the outcomes of sepsis may be enacted on a scale to produce a significant public health impact.

Key Words: Vitamin D, Sepsis, Macrophages, PICU.

\section{*Correspondence to:}

Dr. Vikram Yadav, Resident, Dept. of Paediatrics, S.P Medical College, Bikaner, Rajasthan. Email: vikramyadav246.vy@gmail.com

\section{Article History:}

Received: 03-05-2016, Revised: 12-05-2016, Accepted: 21-05-2016

\begin{tabular}{|l|r|}
\hline \multicolumn{2}{|c|}{ Access this article online } \\
\hline Website: & Quick Response code \\
www.ijmrp.com & \\
\hline DOI: & \\
10.21276/ijmrp.2016.2.3.049 & \\
\hline
\end{tabular}

differentiation and activation of macrophages, dendritic cells and lymphocytes ${ }^{10}$. It has also been found that low $25(\mathrm{OH})$ Vitamin D levels have been associated with increased severity of infection leading to sepsis ${ }^{11}$.

Sepsis is one of the leading causes of death in intensive care unit. The incidence of sepsis remains high despite the increasing array of powerful antibiotics ${ }^{12}$. Higher rate of Vitamin $D$ deficiency is found in patients with sepsis which increases the morbidity, mortality and length of stay in hospital13. Thus the role of Vitamin $D$ in immune system has been increasingly recognized and has a potential therapeutic use. The developing science around vitamin $D$ has begun to reveal potential links between its deficiency and sepsis. The connections between these conditions are still in the early phases of discovery. This was purpose of our study to establish a relationship between level of Vitamin D and sepsis.

\section{MATERIAL \& METHODS}

This study was conducted in Paediatric intensive care unit (PICU) of Department of Paediatrics, S.P. Medical College and Associated Group of Hospitals, Bikaner (Rajasthan). Patients admitted to the PICU who fulfil inclusion criteria were enrolled.

This study was explained to the patient's parents before they are asked to sign the Informed Consent Form. 
Patients of either gender, older than 1 year and younger than 12 years with systemic inflammatory response syndrome (SIRS) with suspected or proven sepsis, admitted in PICU were included for the study.

\section{Criteria of SIRS ${ }^{14}$}

The presence of at least two of the following four criteria, one of which must be abnormal temperature and leucocyte count.

- Core temperature of $>38.5$ degrees $\mathrm{C}$ or $<36$ degrees $\mathrm{C}$

- Tachycardia, defined as mean heart rate of $>2 S D$ above normal for age in the absence of external stimuli, chronic drugs or painful stimuli or otherwise unexplained persistent elevation over a $30 \mathrm{~min}$ to $4 \mathrm{hr}$ time period. For children $<1 \mathrm{yr}$ old, bradycardia is defined as a mean heart rate $<10$ percentile for age in absence of external vagal stimulus, beta blockers drugs, or congenital heart disease or otherwise unexplained persistent depression over a $30 \mathrm{~min}$ time period.

- Mean respiratory rate >2 SD above normal for age or mechanical ventilation for an acute process not related to underlying neuromuscular disease or the receipt of general anaesthesia.

- Leukocyte count elevated or depressed for age (not secondary to chemotherapy -induced leucopenia) or $>10 \%$ immature neutrophils.

For measurement of vitamin $D$, fresh blood sample was taken within 24 hours of admission in PICU and level of vitamin D was measured by VIDAS ${ }^{\circledR} 25 \mathrm{OH}$ Vitamin D Total, which is an automated quantitative test for the determination of 25hydroxyvitamin D Total in human serum or plasma using the ELFA (Enzyme Linked Fluorescent Assay) technique. It reflects vitamin D produced cutaneously and that obtained from food and supplements for a reliable indication of vitamin $D$ status.

The VIDAS@ $25 \mathrm{OH}$ Vitamin D Total reference range is compliant with international clinical recommendations ${ }^{15}$. It enables clinicians to confidently establish a patient's vitamin D status and determine the appropriate supplementation.

\section{Performance}

VIDAS $® 25 \mathrm{OH}$ Vitamin D Total is very well correlated to the Liquid Chromatography-Mass Spectrometry/Mass Spectrometry (LC-MS/MS) reference method. It offers the same high degree of precision and is easy to perform in any lab for rapid results.

Results were analyzed according to following biological analysis value.

- Deficiency $<20 \mathrm{ng} / \mathrm{ml}$ - Insufficiency $-20-30 \mathrm{ng} / \mathrm{ml}$

- Sufficiency $-30-100 \mathrm{ng} / \mathrm{ml}$ - Toxicity $>100 \mathrm{ng} / \mathrm{ml}$

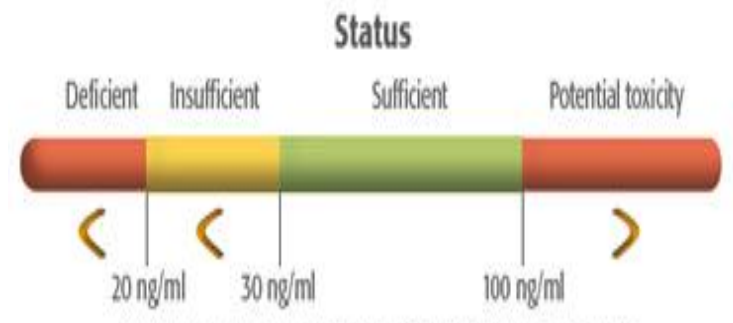

References range of VIDAS 25 OH Vitamin D Total

\section{RESULTS}

The present study observed that 16 were females and 34 were males were statistical analysis, at vitamin $D_{3}$ levels $<20$ and 20-29 the difference was found insignificant $(p>0.05)$ while at vitamin $D_{3}$ level 30-100 the difference was found statistically significant $(p<0.05)$ (Table 1).

According to diagnosis, Most common diagnosis was LRTI (36\%), followed by septicaemia (16\%), meningitis (16\%), Acute asthma (6\%), Acute Liver failure, DKA, Malaria (4\% each), Age with severe dehydration, shock, GBS, Pertusis encephalopathy, septic arthritis and UTI (2\% each) (Table 2).

According to outcome the difference was found insignificant at vitamin $D_{3}$ level $<20$ and 20-29 while significant difference was found at vitamin $D_{3}$ level 30-100 (Table 3).

\section{DISCUSSION}

In the present study out of the total 50 patients 30 patients $(60 \%)$ were in the deficient group. 12 patients 924\%) were in the insufficient group and 8 patients (16\%) were in the sufficient group. hence $42(84 \%)$ patients had vitamin $D_{3}$ levels $<30 \mathrm{ng} / \mathrm{ml}$. Our results were similar to a study done by Ginde et al ${ }^{11}$, Jeng et $\mathrm{al}^{16}$, Satheesh et $\mathrm{al}^{17}$ and Amrein et al ${ }^{18}$ they suggested that vitamin $D$ has important modulatory effects on the innate immune response to LPS-induced sepsis. In the year 2006 Sadeghi et al19 demonstrated that human monocytes stimulated with LPS and treated with 1,25-dihydroxyvitamin $\mathrm{D}(1,25(\mathrm{OH}) 2 \mathrm{D})$, showed dosedependent decreases in TLR2 and TLR4 synthesis, with an increase in CD14, a TLR co-stimulatory molecule. They further found that 1,25(OH)2D decrease TNFa and tissue factor, both end products of LPS activation and important inflammatory molecules in sepsis. These effects were reversed with the introduction of a VDR antagonist, reinforcing a key role of vitamin $D$ in this signaling mechanism.

Table 1: Distribution of cases according to sex

\begin{tabular}{|c|c|c|c|c|c|c|c|c|}
\hline \multirow[t]{3}{*}{ Sex } & \multicolumn{6}{|c|}{ Vitamin $\mathrm{D}_{3}$ Level } & \multicolumn{2}{|c|}{ Total } \\
\hline & \multicolumn{2}{|c|}{$<20$ (Deficiency) } & \multicolumn{2}{|c|}{ 20-29 (Insufficiency) } & \multicolumn{2}{|c|}{ 30-100 (Sufficiency) } & & \\
\hline & No. & $\%$ & No. & $\%$ & No. & $\%$ & No. & $\%$ \\
\hline Female & 12 & 40.0 & 4 & 33.3 & 0 & - & 16 & 32.0 \\
\hline Male & 18 & 60.0 & 8 & 66.7 & 8 & 100.0 & 34 & 68.0 \\
\hline Total & 30 & 100 & 12 & 100 & 8 & 100 & 50 & 100 \\
\hline$\chi^{2}$ & \multicolumn{2}{|c|}{2.205} & \multicolumn{2}{|c|}{0.019} & \multicolumn{2}{|c|}{4.481} & & \\
\hline $\mathbf{P}$ & \multicolumn{2}{|c|}{$>0.05$} & \multicolumn{2}{|c|}{$>0.05$} & \multicolumn{2}{|c|}{$<0.05$} & & \\
\hline
\end{tabular}


Table 2: Distribution of cases according to examination of diagnosis

\begin{tabular}{|c|c|c|c|c|c|c|c|c|}
\hline \multirow[t]{3}{*}{ Diagnosis } & \multicolumn{6}{|c|}{ VITD3GP } & \multicolumn{2}{|c|}{ Total } \\
\hline & \multicolumn{2}{|c|}{$\begin{array}{c}<20 \\
\text { (Deficiency) }\end{array}$} & \multicolumn{2}{|c|}{ 20-29 (Insufficiency) } & \multicolumn{2}{|c|}{$\begin{array}{c}30-100 \\
\text { (Sufficiency) }\end{array}$} & \multirow[b]{2}{*}{ No. } & \multirow[b]{2}{*}{$\%$} \\
\hline & No. & $\%$ & No. & $\%$ & No. & $\%$ & & \\
\hline Acute Asthma & 1 & 3.3 & 2 & 16.7 & 0 & - & 3 & 6.0 \\
\hline Acute Liver Failure & 1 & 3.3 & 1 & 8.3 & 0 & - & 2 & 4.0 \\
\hline AGE with Severe Dehydration, & 1 & 3.3 & 0 & - & 0 & - & 1 & 2.0 \\
\hline \multicolumn{9}{|l|}{ Shock } \\
\hline DKA & 2 & 6.7 & 0 & - & 0 & - & 2 & 4.0 \\
\hline GBS & 0 & - & 1 & 8.3 & 0 & - & 1 & 2.0 \\
\hline LRTI & 12 & 40.0 & 2 & 16.7 & 4 & 50.0 & 18 & 36.0 \\
\hline Malaria & 1 & 3.3 & 0 & - & 1 & 12.5 & 2 & 4.0 \\
\hline Meningitis & 4 & 13.3 & 3 & 25.0 & 1 & 12.5 & 8 & 16.0 \\
\hline Pertusis Encephalopathy & 0 & - & 1 & 8.3 & 0 & - & 1 & 2.0 \\
\hline Septic Arthritis & 1 & 3.3 & 0 & - & 0 & - & 1 & 2.0 \\
\hline Septicemia & 5 & 16.7 & 1 & 8.3 & 2 & 25.0 & 8 & 16.0 \\
\hline UTI & 1 & 3.3 & 0 & - & 0 & - & 1 & 2.0 \\
\hline Total & 30 & 100 & 12 & 100 & 8 & 100 & 50 & 100 \\
\hline
\end{tabular}

Table 3: Distribution of cases according to outcome

\begin{tabular}{|c|c|c|c|c|c|c|c|c|}
\hline \multirow[t]{3}{*}{ Outcome } & \multicolumn{6}{|c|}{ Vitamin $\mathrm{D}_{3}$ Level } & \multicolumn{2}{|c|}{ Total } \\
\hline & \multicolumn{2}{|c|}{$<20$ (Deficiency) } & \multicolumn{2}{|c|}{ 20-29 (Insufficiency) } & \multicolumn{2}{|c|}{ 30-100 (Sufficiency) } & & \\
\hline & No. & $\%$ & No. & $\%$ & No. & $\%$ & No. & $\%$ \\
\hline Discharge & 26 & 86.7 & 11 & 91.7 & 7 & 87.5 & 44 & 88.0 \\
\hline Expired & 4 & 13.3 & 1 & 8.3 & 0 & - & 5 & 10.0 \\
\hline Referred & 0 & - & 0 & - & 1 & 12.5 & 1 & 2.0 \\
\hline Total & 30 & 100 & 12 & 100 & 8 & 100 & 50 & 100 \\
\hline$\chi^{2}$ & \multicolumn{2}{|c|}{2.348} & \multicolumn{2}{|c|}{0.384} & \multicolumn{2}{|c|}{6.202} & \multicolumn{2}{|c|}{6.441} \\
\hline $\mathbf{P}$ & \multicolumn{2}{|c|}{$>0.05$} & \multicolumn{2}{|c|}{$>0.05$} & \multicolumn{2}{|c|}{$<0.05$} & \multicolumn{2}{|c|}{0.169} \\
\hline
\end{tabular}

In our study most common diagnosis was lower respiratory tract infection (36\%). Other diagnoses were septicemia (16\%), meningitis $(16 \%)$, acute asthma $(6 \%)$ acute liver failure $(4 \%)$, diabetic ketoacidosis (4\%), malaria (4\%), acute gastroenteritis with shock $(2 \%)$, GBS $(2 \%)$, pertussis encephalopathy $(2 \%)$, septic arthritis (2\%) and urinary tract infection (2\%). Our observations were similar to a study done at St. Vincent Hospital, Sydney by Lee et $\mathrm{al}^{20}$ in 2009 and Azim et al21 in 2013. Vitamin D acts in the local tissue response to infection ${ }^{22}$ and is integral to the production of antimicrobial peptides (AMPs) ${ }^{23}$. A landmark study by Liu and colleagues ${ }^{24}$ in 2006 revealed the critical role of vitamin $D$ in the macrophage response to Mycobacterium tuberculosis via the AMP cathelicidin. The active fragment of cathelicidin is LL-37, which has been shown to be produced by phagocytic leukocytes, mucosal epithelium, and keratinocytes and to be present in mucosal secretions and plasma ${ }^{25}$. Its immune functions include direct bactericidal activity as well as disruption of Pseudomonas aeruginosa biofilms, promotion of phagocytosis and reactive oxygen species, and chemotaxis of other immune cells to sites of infection ${ }^{25}$

The results of the clinical science of vitamin $D$ and sepsis are mixed, yet it would be simplistic to dismiss this field of research on such grounds. The failure of vitamin $D$ to produce effects in the current observational literature may be a result of study design and insufficient power to reveal a mortality difference. Interest for a treatment affecting sepsis mortality, it may be unrealistic to power a study to show such a difference.

\section{CONCLUSION}

The multiple functions of vitamin $D$ in the immune system's response to infection suggest it may be an integral component in combating sepsis. Furthermore, clinical data also point toward a role of vitamin $D$ and critical illness but a direct relationship with sepsis and its severity and outcomes is yet to be determined by further research. the current picture of vitamin $D$ and sepsis is one of a research field early in its course with many important links that provide fertile ground for further investigation. Such investigation is warranted as vitamin $D$ is inexpensive and safe to administer and even incremental benefits in the outcomes of sepsis may be enacted on a scale to produce a significant public health impact.

\section{REFERENCES}

1. Holick MF. High prevalence of vitamin $D$ inadequacy and implications for health. Mayo Clin. Proc. 2006; 81(3):353-73.

2. Calvo MS, Whiting SJ, Barton CN. Vitamin $D$ intake: a global perspective of current status. J. Nutr. 2005; 135(2):310-6.

3. Norman AW. From vitamin $D$ to hormone $D$ : fundamentals of the vitamin $D$ endocrine system essential for good health. Am. J. Clin. Nutr 2008; 88 2): 491S-499S. 
4. Wang TT, Tavera-Mendoza LE, Laperriere D, Libby E, MacLeod NB, Nagai $Y$, et al. Large-scale in silico and microarray-based identification of direct 1,25-dihydroxyvitamin D3 target genes. Mol Endocrinol 2005; 19:2685-95.

5. Autier P, Gandini S. Vitamin D supplementation and total mortality: a meta-analysis of randomized controlled trials. Arch Intern Med 2007; 167:1730-7.

6. Holick MF, Binkley NC, Bischoff-Ferrari HA, Gordon CM, Hanley DA, Heaney RP, et al. Endocrine Society. Evaluation, treatment, and prevention of vitamin $\mathrm{D}$ deficiency: an Endocrine Society clinical practice guideline. J Clin Endocrinol Metab 2011; 96:1911- 30.

7. Yamshchikov AV, Desai NS, Blumberg HM, Ziegler TR, Tangpricha V. Vitamin $D$ for treatment and prevention of infectious diseases: a systematic review of randomized controlled trials. Endocr Pract 2009; 15:438-49.

8. Sokol SI, Tsang P, Aggarwal V, Melamed ML, Srinivas VS. Vitamin $\mathrm{D}$ status and risk of cardiovascular events: lessons learned via systematic review and meta-analysis. Cardiol Rev 2011; 19:192-201.

9. Zhao G, Ford ES, Li C, Croft JB. Serum 25-hydroxyvitamin D levels and all-cause and cardiovascular disease mortality among US adults with hypertension: the NHANES linked mortality study. J Hypertens 2012; 30:284-9.

10. Hewison M. Vitamin $D$ and the immune system: new perspectives on an old theme. Endocrinol Metab Clin North Am. 2010; 39:365-79.

11. Ginde AA, Camargo CA, Jr., Shapiro NI. Vitamin D insufficiency and sepsis severity in emergency department patients with suspected infection. Acad Emerg Med 2011; 18:551-4.

12. Kress JP, Hall JB. Approach to a patient with critical illness. Harrison's Principles of Internal Medicine. Vol 2. 18th ed. USA: McGraw Hill; 2012: p2202.

13. Venkatram S, Chilimuri S, Adrish M, Salako A, Patel M, DiazFuentes G. Vitamin D deficiency is associated with mortality in the medical intensive care unit. Crit Care 2011; 15:292.

14. Zhang Y, Leung DY, Richers BN, Liu Y, Remigio LK, et al. Vitamin d inhibits monocyte/macrophage proinflammatory cytokine production by targeting MAPK phosphatase-1. J Immunol 2012; 188:2127-2135.

15. Institute of Medicine. Dietary reference intakes for calcium and vitamin D Washington DC; National Academies Press 2010.

16. Jeng L, Yamshchikov AV, Judd SE, Blumberg HM, Martin GS, et al. Alterations in vitamin $D$ status and anti-microbial peptide levels in patients in the intensive care unit with sepsis. J Transl Med 2009; 7:28.

17. Satheesh $P$, Verma S, Singhi S, Bansal A. Prevalence of vitamin
D deficiency among children with sepsis, its assocaiton with sepsis severity and its outcome in a pediatric IUC. Critical Care 2013; 17(suppl 4):35.

18. Amrein $K$, Venkatesh $B$. Vitamin $D$ and the critically ill patient. Curr Opin Clin Nutr Metab Care. 2012; 15:188-193.

19. Sadeghi K, Wessner B, Laggner U, Ploder M, Tamandl D, et al. Vitamin D3 down-regulates monocyte TLR expression and triggers hyporesponsiveness to pathogen-associated molecular patterns. Eur $\mathrm{J}$ Immunol 2006; 36:361-370.

20. Lee P, Eisman JA, Center JR. Vitamin D deficiency in critically ill patients. N Engl J Med 2009; 360: 1912-4.

21. Azim A, Ahmed A, yadav S, Baronia AK, Gurjar $M$ et al. Prevalence of vitamin $D$ deficiency in critically ill patients and its influence on outcome: experience from a tertiary care centre in North India (an observational study). J Intensive Care 203; 1(1):14.

22. Nelson CD, Reinhardt TA, Beitz DC, Lippolis JD. In vivo activation of the intracrine vitamin $D$ pathway in innate immune cells and mammary tissue during a bacterial infection. PLOS One 2010; 5:e15469.

23. Kamen DL, Tangpricha V. Vitamin D and molecular actions on the immune system: modulation of innate and autoimmunity. J Mol Med (Berl) 2010; 88:441-450.

24. Liu PT, Stenger S, Li H, Wenzel L, Tan BH, et al. Toll-like receptor triggering of a vitamin D-mediated human antimicrobial response. Science 2006; 311:1770-1773.

25. Nijnik A, Hancock RE. The roles of cathelicidin LL-37 in immune defences and novel clinical applications. Curr Opin Hematol 2009; 16:41-47.

\section{Source of Support: Nil. Conflict of Interest: None Declared.}

Copyright: (c) the author(s) and publisher. IJMRP is an official publication of Ibn Sina Academy of Medieval Medicine \& Sciences, registered in 2001 under Indian Trusts Act, 1882.

This is an open access article distributed under the terms of the Creative Commons Attribution Non-commercial License, which permits unrestricted non-commercial use, distribution, and reproduction in any medium, provided the original work is properly cited.

Cite this article as: Vikram Yadav, Nishant Ahmad, R K Soni, Monika. To Study the Vitamin D Status in Children with Sepsis Admitted in Intensive Care Unit of a Tertiary Care Centre of NorthWest Rajsthan. Int J Med Res Prof. 2016; 2(3):226-29. 